ECCOMAS

Proceedia

\author{
COMPDYN 2021 \\ $8^{\text {th }}$ ECCOMAS Thematic Conference on \\ Computational Methods in Structural Dynamics and Earthquake Engineering \\ M. Papadrakakis, M. Fragiadakis (eds.)
} Streamed from Athens, Greece, 28 - 30 June 2021

\title{
EXPERIMENTAL TESTS AND NUMERICAL STUDY OF THE PLASTIC CYCLIC BEHAVIOUR OF A STEEL BEAM-TO-COLUMN CONNECTION
}

\author{
G.C. Manos, A. Nalmpantidou \\ Laboratory for Strength of materials and Structures \\ Dpt. Civil Engineering, A.U.Th.pt. Civil Engineering, A.U.Th. \\ Egnatia Odos, Panepistimioupoli \\ gcmanos@civil.auth.gr, a.nalmpantidou@posteo.de
}

\begin{abstract}
Steel beam-to-column connections under a cyclic sinusoidal loading history were studied. The investigation of the cyclic response of the steel beam-to-column connections contained an experimental and numerical part. The experimental part included a number of full-scale specimens having a cross section of IPE240 or IPE300 and a height of 1.0m which were rigidly connected to a much stiffer steel beam thus representing a steel beam-to-column connection. These specimens were tested to failure being subjected to a cyclic sinusoidal point load of continuously increasing amplitude. Each specimen experienced yielding and plastic rotation till the final damage, which occurred either in the form of local instability of the flanges or fracture. Next, a numerical study is performed in an effort to simulate the observed behaviour of these steel beam-to-column connections and their response is presented and discussed. The material test data for the numerical simulation of the steel beam-to-column connection were provided from simple steel coupons which were taken from the T-beam specimens after testing. Experimental and numerical results of the beam-to-column connections are presented and discussed in this paper. It can be concluded that the employed numerical simulation can be quite successful in yielding realistic prediction of the cyclic response of the steel beam-tocolumn, provided that the material model in this numerical simulation was equipped with the appropriate values for the parameters defining the material constitutive law from the experimental test data.
\end{abstract}

Keywords: Steel beam-to-column connection, Simple steel coupons, cyclic response, Numerical Simulation, Comparison of measured and predicted response, strain rate effects 


\section{INTRODUCTION}

Steel frame structures are commonly used in seismic areas because of their excellence on seismic resistance. This type of structures are usually composed of moment resistant frames whereby the performance of beam-to-column connections are of particular importance especially when these structures are subjected to strong earthquake ground motions $[1,2,5]$. Usually these connections undergo large moment reversals during the earthquake excitation, thus it is important to exhibit stable plastic flexural response in order to provide dissipative capability, without the development of undesired damage patterns, and in this way prevent any kind of local or global instability. However, two recent earthquakes, in Northridge, California 1994 and Kobe Japan 1995, revealed the vulnerability of this type of construction. Premature cracks were observed at welded connections of steel beam-to-column joints leading to brittle failure without prior warning (obvious yielding) at the area around the weld. Such a failure mode or the development of local buckling when beam-to-column connections undergo lowcycle fatigue seismic-type of loading is of particular research interest [3, 4, 9, 14].

The fatigue life of steel beam-to-column joints depends on the amplitude of the imposed loading cycles and the hysteretic behavior of the constituent material that is linked with the amplitude and rate of the developing plastic strains. In order to investigate the fatigue life of steel beam-to-column joints several fatigue testing investigations have been proposed leading to tests that can be categorized in two groups. Testing regimes in which the elastic strain amplitude is higher than the plastic strain amplitude and testing regimes in which the plastic strain dominates. The first type of tests is generally referred as high cycle fatigue (HCF); these tests typically involve more than $10^{6}$ cycles to cause failure. The second type of tests is named low cycle fatigue (LCF) test and the number of cycles to failure generally ranges from $10^{2}$ to $10^{4}$ cycles and this is usually employed for testing the seismic performance of steel beam-to-column joints $[6,8,11,12,15]$.

The current work studies the performance of steel beam-to-column joints first by examining steel beam-to-column welded joint specimens at the laboratory subjecting them to cyclic seismic-type low-cycle fatigue loading as is explained in section 2. Next, the performance of the same specimens is simulated numerically. Similar studies have been performed in the past by other researchers. Despite the fact that many similar experiments have been performed in the past $[6,8]$, the current experimental investigation was considered as necessary in order to provide at first hand all the information required for the numerical analyses. That is, the exact geometric and material characteristics of the specimens as well as specific information on the type of loading conditions and on the measured response. The numerical simulation is performed utilizing a commercial software package that is thought to be suitable to simulate the observed response and the non-linearities that developed and included large plastic strains and local instabilities.

\section{MATERIALS AND EXPERIMENTAL SETUP}

\subsection{Tested specimens}

Two full-scale specimens, namely T-Beam 8 and T-Beam 8R1 INV have been constructed with prototype steel cross sections in order to form a beam-to-column joint. Both specimens were of the same geometry and used as the beam part a IPE 300 steel section and as the column part a HEA 300 steel section. These two parts were welded together, as shown in figures 1 and 2, to form the beam-to-column connection to be tested .

The IPE 300 beam was to a steel base plate having a thickness of $20 \mathrm{~mm}$ welded and this steel plate in turn was bolted to the HEA 300 column (figure 1 and 2). Furthermore, in order 
to avoid the brittle type of failure at the welds joining the IPE 300 beam part with the base steel plate two or six $20 \mathrm{~mm}$ thick steel stiffeners of triangular shape (with a height of $150 \mathrm{~mm}$ and width of $150 \mathrm{~mm}$ ) were welded at either side of the IPE 300 section connecting its flanges with the base plate as shown in figures 1 and 2. The T-Beam 8 specimen had in total two identical triangular steel stiffeners on each side of the flanges welded and the T-Beam 8R1 INV specimen had in total 6 steel stiffeners 3 evenly spaced on each side of the flanges. The height of the IPE 300 beam part was $1200 \mathrm{~mm}$ and was connected on its upper part with the forcing fixtures that were provided by a double acting hydraulic actuator. This actuator was controlled by a servo-hydraulic digital electronic controller providing the desired imposed cyclic horizontal displacement amplitude at a distance of $1000 \mathrm{~mm}$ from the base plate. The two IPE 300 beam-to-column connection specimens were tested as shown in figures 1 and 2. Both specimens were of the same overall geometry having webs with thickness equal to $7 \mathrm{~mm}$. The flange thickness varied from $10.2 \mathrm{~mm}$ for the west flange and $10.5 \mathrm{~mm}$ for the east flange.

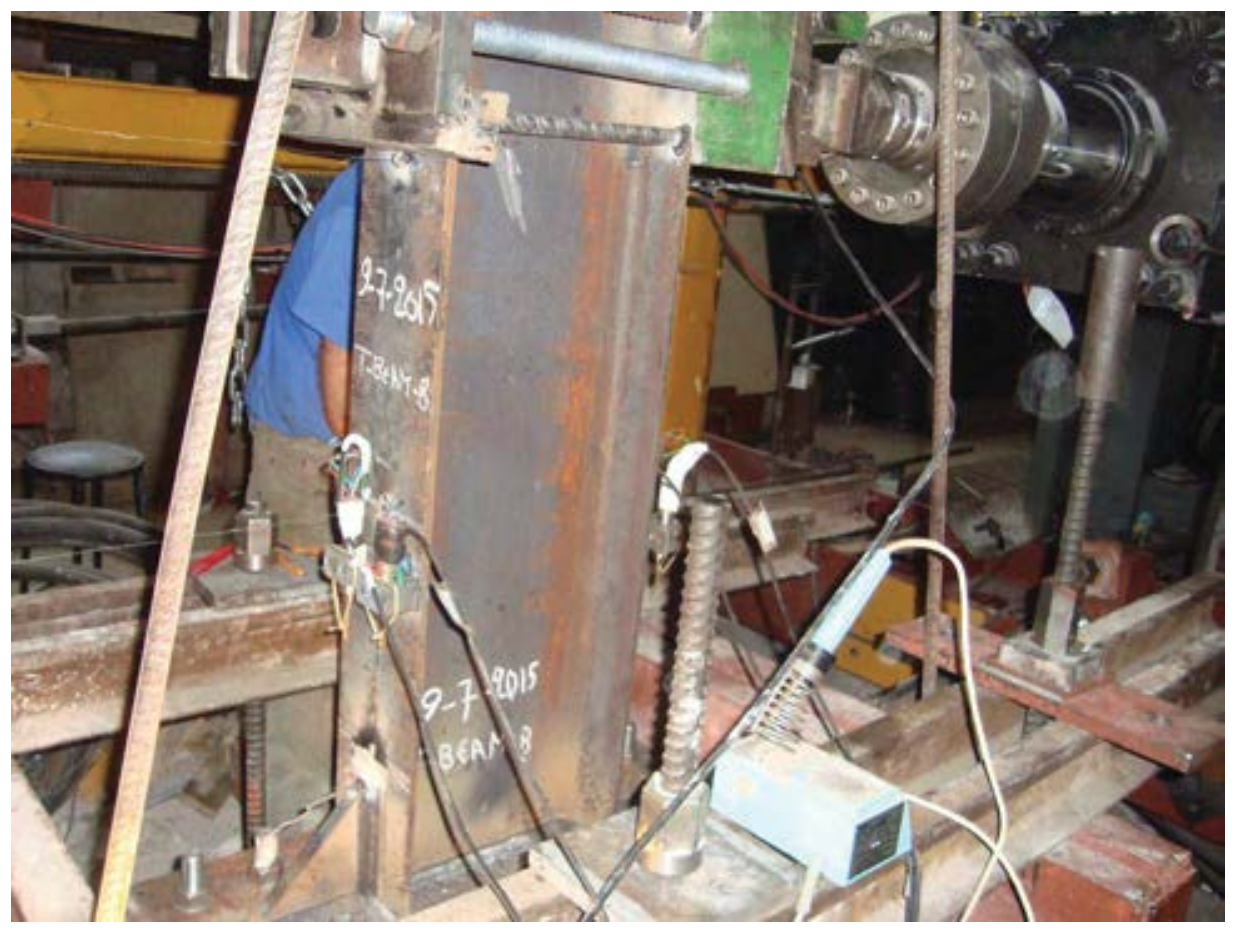

Figure 1. Details of the experimental setup with the tested IPE 300 T-Beam 8 beam-to-column joint specimen 


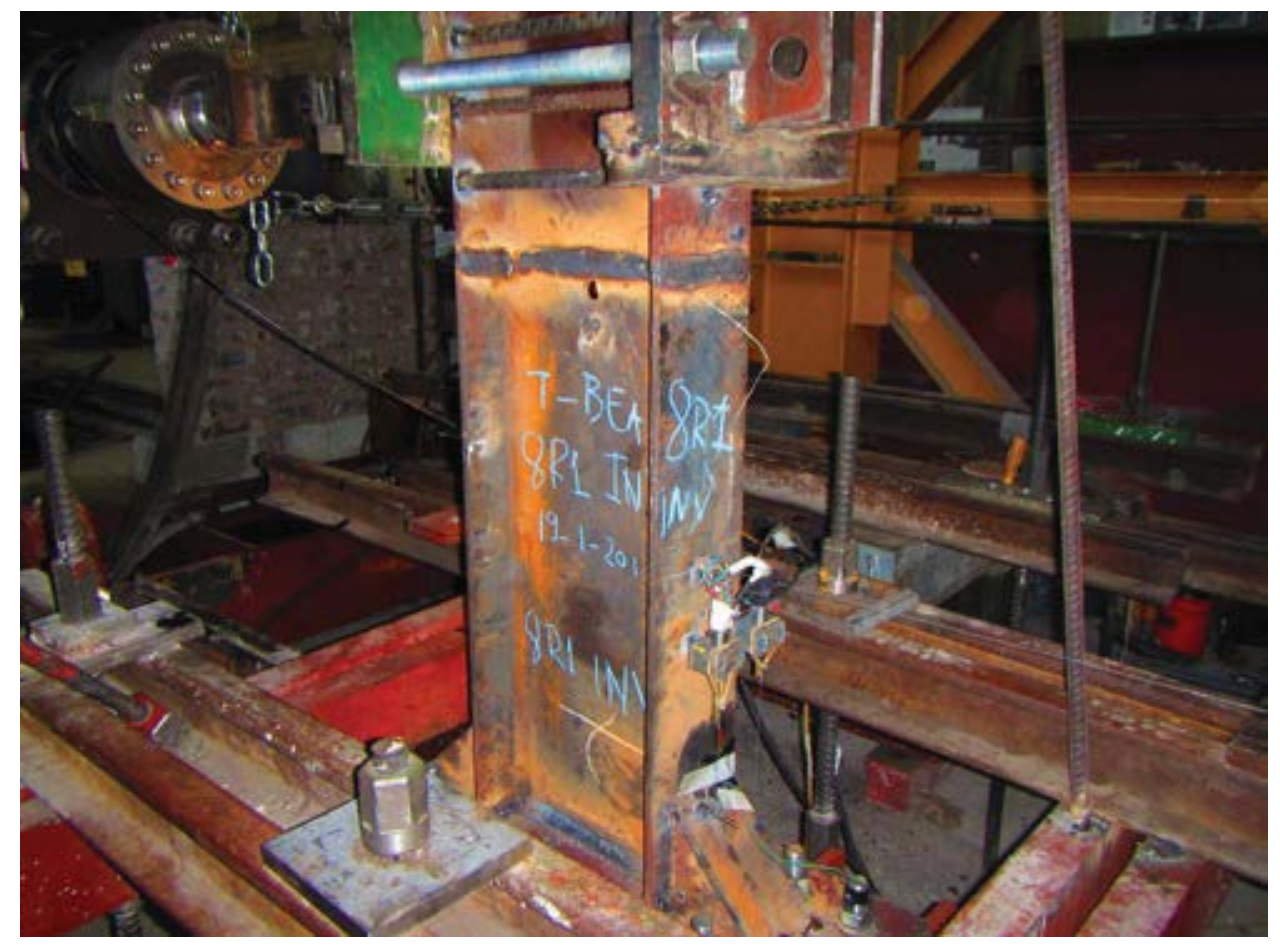

Figure 2. Details of the experimental setup with the tested IPE 300 T-Beam 8R1 INV beam-to-column joint specimen

\subsection{Loading arrangement}

The tested specimens were subjected to a cyclic seismic-type loading arrangement. An extensive discussion on the loading protocols was presented by Krawinkler [11]. This is a very important and difficult issue as on one hand it is believed that it influences the resulting performance and on the other hand it poses demands on the capabilities of the experimental facility $[6,7,8,11,12,15]$. As this work at its present stage aims to produce results that will be utilized for validating the numerical capabilities of existing software rather than checking the validity of code provisions the used loading protocol does not comply exactly with ones suggested by Krawinkler and other researchers [6, 7, 11, 15]. Instead, a series of sinusoidal horizontal cyclic displacements were used and were imposed on the top of the IPE 300 beam part, as shown in figures 1,2 and 4 . Both specimens were rigidly attached on the strong floor of the Laboratory of Strength of Materials and Structures of Aristotle University. The hydraulic actuator was attached on the strong metal frame which together with the strong floor forms this experimental facility. The imposed horizontal displacement and the resulting horizontal load leads to the development of a bending moment at the beam-to-column connection which, if of sufficient amplitude, is expected to bring this part of the beam-to-column connection to a certain limit state condition, as will be explained in section 3. The imposed horizontal displacement in amplitude and frequency content is controlled by the electronic servo-controller. A relatively simple imposed displacement protocol is depicted in figure 3. It consists of thirteen (13) groups of 3 full sinusoidal cycles. In each group the imposed maximum displacement amplitude remains constant and keeps gradually increasing from one group to the next in a prescribed manner, as a percentage of the maximum target displacement. The difficulty in imposing this protocol accurately lies on the fact that the target displacement is known at best through predictions that may differ considerably from the actual target displacement that, 
when imposed, will produced the desired phenomena. The protocol depicted in this figure was adopted in the current study in a general sense. That is, the amplitude of the imposed horizontal displacement kept increasing from one group to the next till the plastification of the tested specimens led to some type of failure, as will be described in section 3. One distinct difference in the followed loading protocol for the specimen T-Beam 8 is the fact that the frequency content was relatively low $(0.005 \mathrm{~Hz})$ as to allow this test to be characterized as a dynamic test accompanied with low level of strain rate. On the contrary, the loading protocol for T-Beam 8R1 INV specimen was relatively high $(0.1 \mathrm{~Hz})$ that is characterized as cyclic test of relatively medium level strain rate.

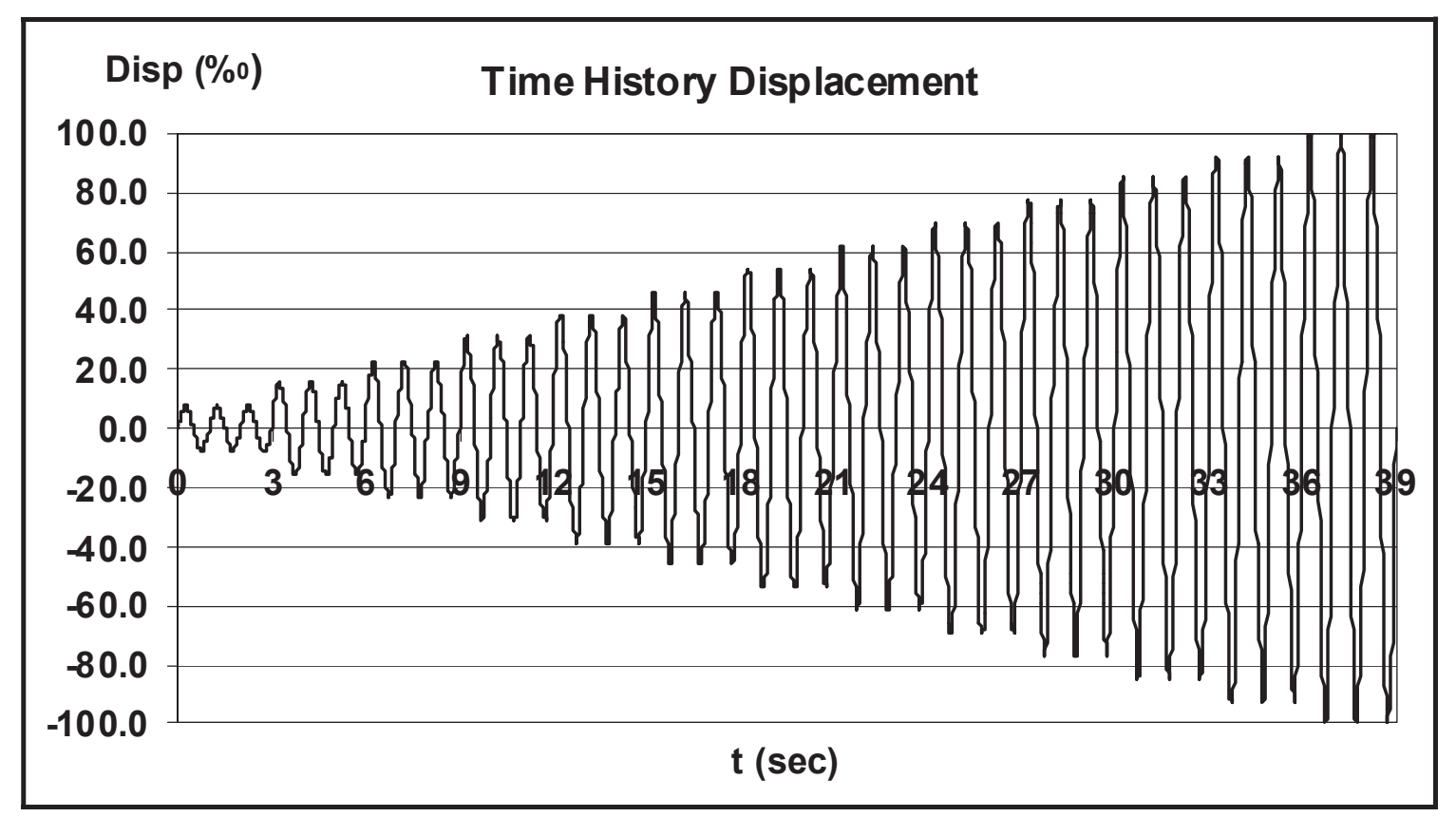

Figure 3. Typical cyclic seismic-type imposed displacement protocol for low fatigue loading

\subsection{Instrumentation}

Instrumentation was provided capable to record the dynamic response of the specimen at the top in terms of imposed horizontal displacement (LVDT 01, figure 4) and horizontal force. In addition, four displacement transducers (LVDT 02, LVDT 03, LVDT 04 and LVDT 05) were attached to the specimen in order to record the relative vertical displacement of two sets of horizontal cross sections of each specimen near the plastification zone (figures 1,2 and 4). The first set of horizontal cross sections was that at the base, where the IPE 300 part was welded at the base steel plate) and the one 500mm higher. Utilizing LVDT 02 and LVDT 03 the relative elongation or shortening between these two cross sections of the specimen was measured at the flanges of both sides of the IPE 300 section. The second set of horizontal cross sections was that at $150 \mathrm{~mm}$ from the base, where the triangular stiffeners ended, and the one 100mm higher. Utilizing LVDT 03 and LVDT 04 the relative elongation or shortening between these two cross sections of the specimen was measured at the flanges of both sides of the IPE 300 section. In this way, it became possible to deduce from the measured response the rotation between the first and the second set of these horizontal cross sections. The second set of horizontal cross sections is of particular importance as the highly plastified region (plastic hinge), which was expected to develop during the experimental sequence, lies between the 
horizontal cross-sections of the second set. Indeed, the used instrumentation was able to capture the plastification of this region from the initial stages of yielding till the final stages of local instability. In addition, a set of strain gauges was also provided in order to control in a different way the initiation and development of plastification in this zone.

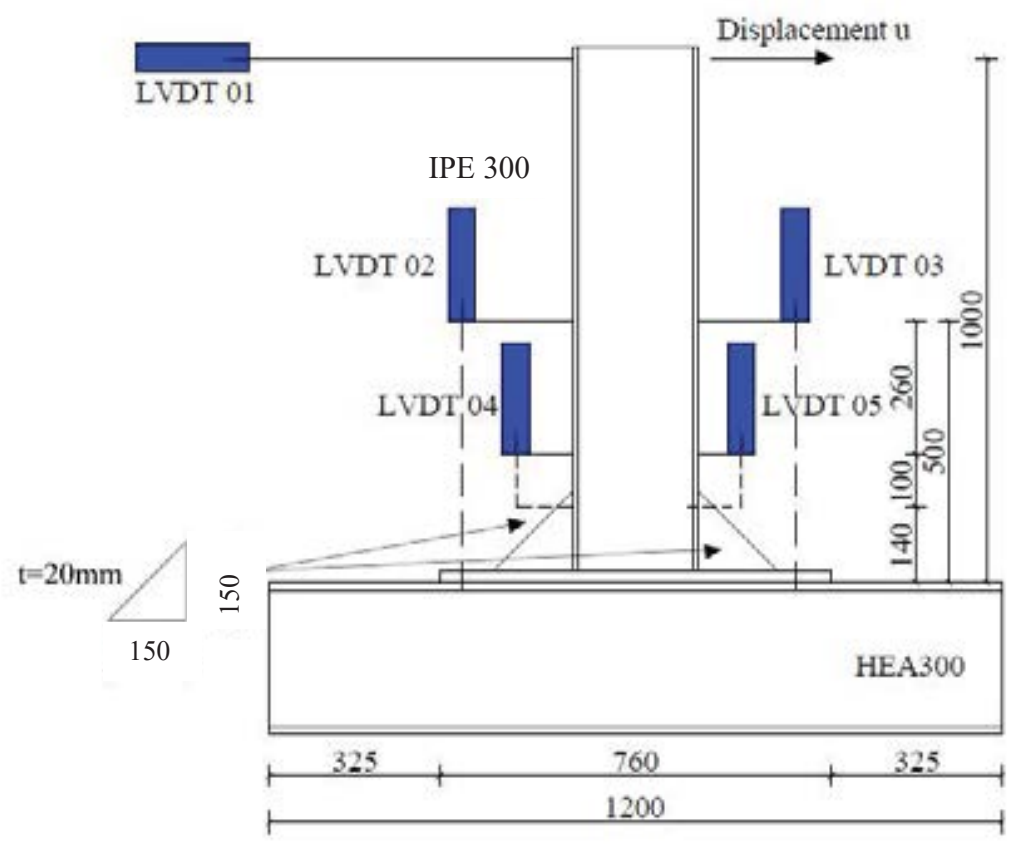

Figure 4. Experimental set-up with the geometry of the specimens, the instrumentation and loading

Figures 5 and 6 depict the instrumentation of this zone near the beam-to-column joint. The used hydraulic actuator can also be seen in figure 5 whereas in figure 6 the vertical displacement transducer utilized to measure the relative elongation or shortening between two horizontal cross sections above the stiffener having a distance between them equal to $100 \mathrm{~mm}$ can also be seen (second set of horizontal cross sections).

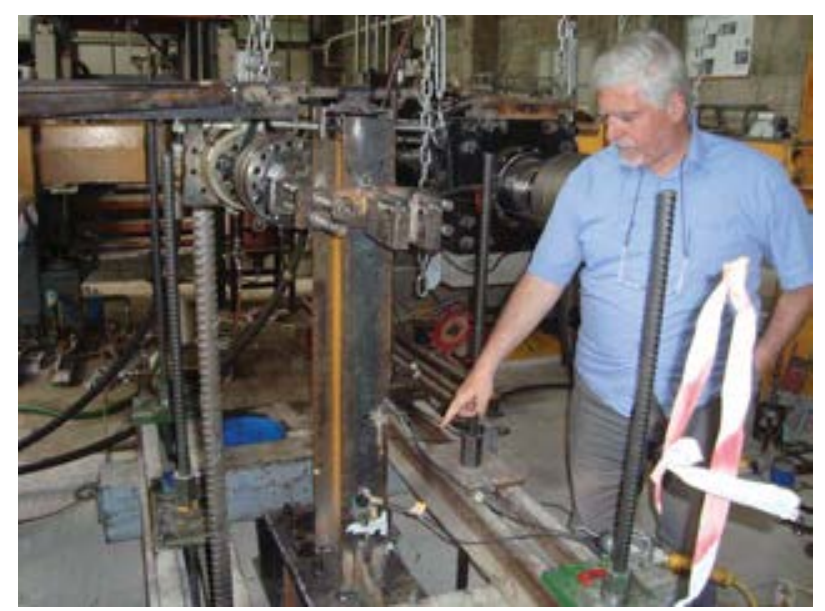

Figure 5. Instruments located near the beam-to-column joint.

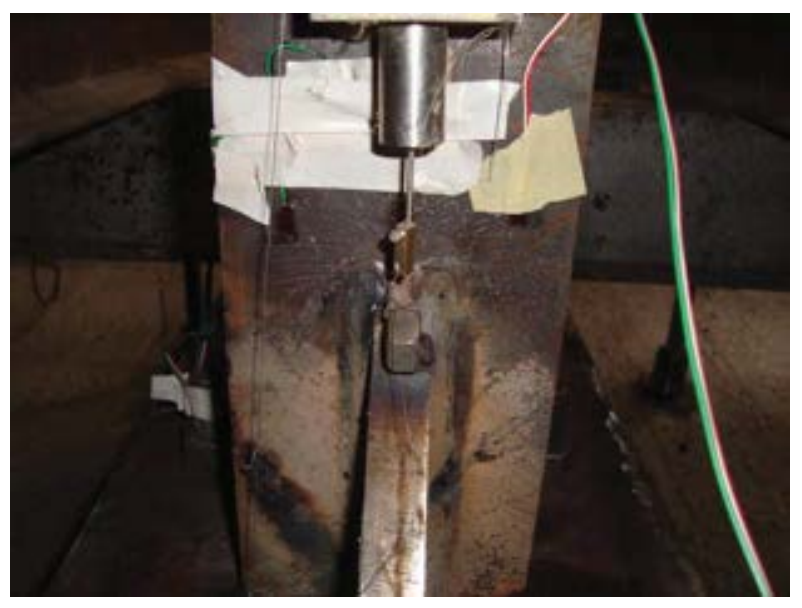

Figure 6. Measuring the relative elongation/shortening between two horizontal cross sections above the stiffener 


\subsection{Steel tensile properties}

In order to input the proper information related to the steel characteristic in the finite element program monotonic tensile tests from similar T-Beam IPE300 beams and cyclic tests from T-Beam 8 with different loading frequencies were performed with coupons taken from the specimens. These coupons were taken from the flanges of the specimens after the completion of the relevant test sequence. In order to measure the material properties of the virgin steel prior to any plastification and permanent straining these coupons were taken from the upper part of the IPE 300 beam sections near the section where the imposed displacement was applied. More detailed information about the material steel coupons and the corresponding results are given in the work of Manos G.C. and Nalmpantidou A. [18].

\section{OBSERVED PERFORMANCE AND CORRESPONDING MEASUREMENTS.}

\subsection{Observed over-all performance and actual damage}

Each specimen experienced plastic rotation above the stiffeners that was captured by the employed instrumentation. Despite the fixity of the attachment of the specimens on the strong floor part of the imposed horizontal displacement was consumed by the rotation of the specimen at its fixed base as well as of the elastic response along the height apart from the plastic rotation that developed at the desired location above the stiffeners. Fortunately, despite the limitations of the capabilities of the experimental facility it was possible to attain the plastic limit state for both studied specimens and produce the expected form of damage. This is depicted in figures 7 for specimen T-Beam 8 and figure 8 for specimen T-beam 8 R1 INV.
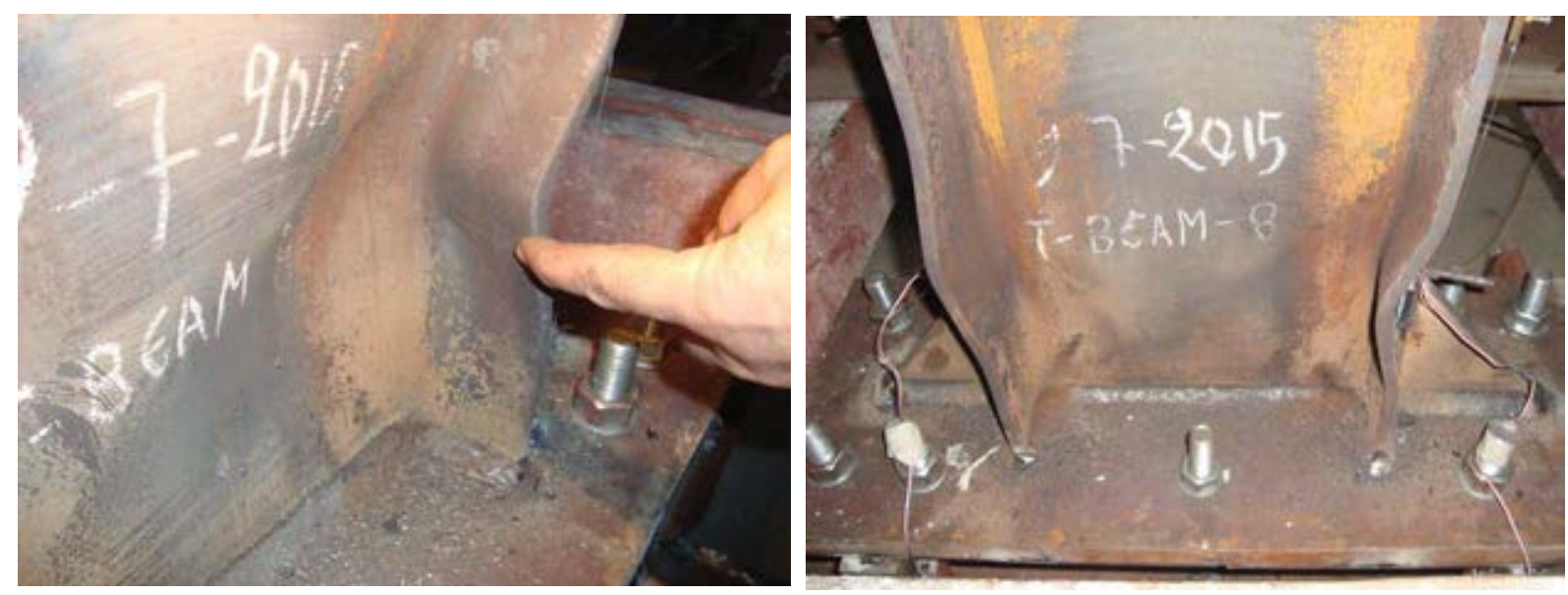

Figure 7. Plastification of specimen T-Beam 8 at the end of test - 11 


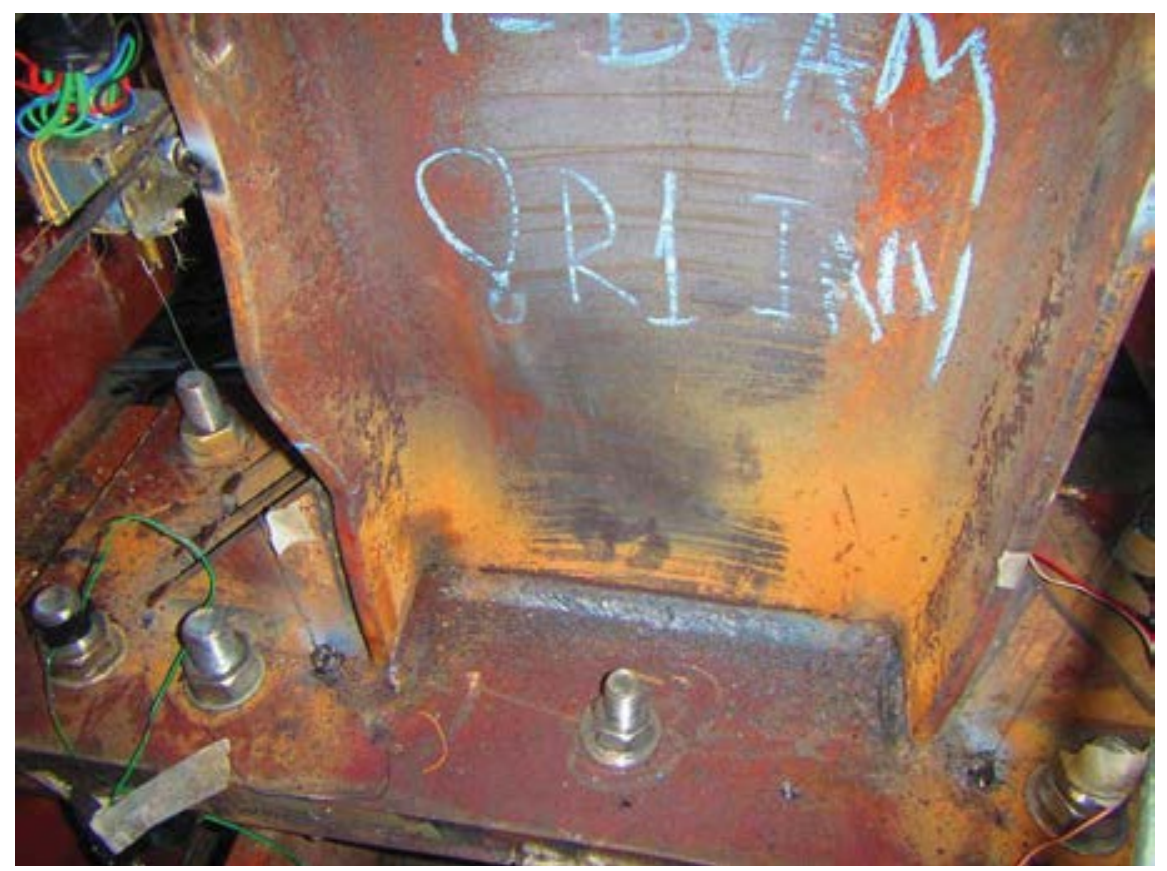

Figure 8. Plastification of specimen T-Beam 8R1 INV at the end of test - 14

\subsection{Measured response in terms of plastic rotations at the plastic hinge.}

Figure 9, depicts the full loading sequence in terms of horizontal displacement at the top of the specimen T-Beam 8 that could be deduced from the employed instrumentation as directly linked with the elastic/plastic rotation at the zone of the specimen extending at a length of $100 \mathrm{~mm}$ above the stiffeners of the IPE 300 beam (figures 4 and 6). The corresponding development of the plastic rotation with time in this plastic hinge region is shown in figure 10 . The imposed loading history in terms of plastic hinge rotation and the corresponding horizontal displacement at the top of specimen T-Beam 8R1 INV is shown in figure 11 and 12. 


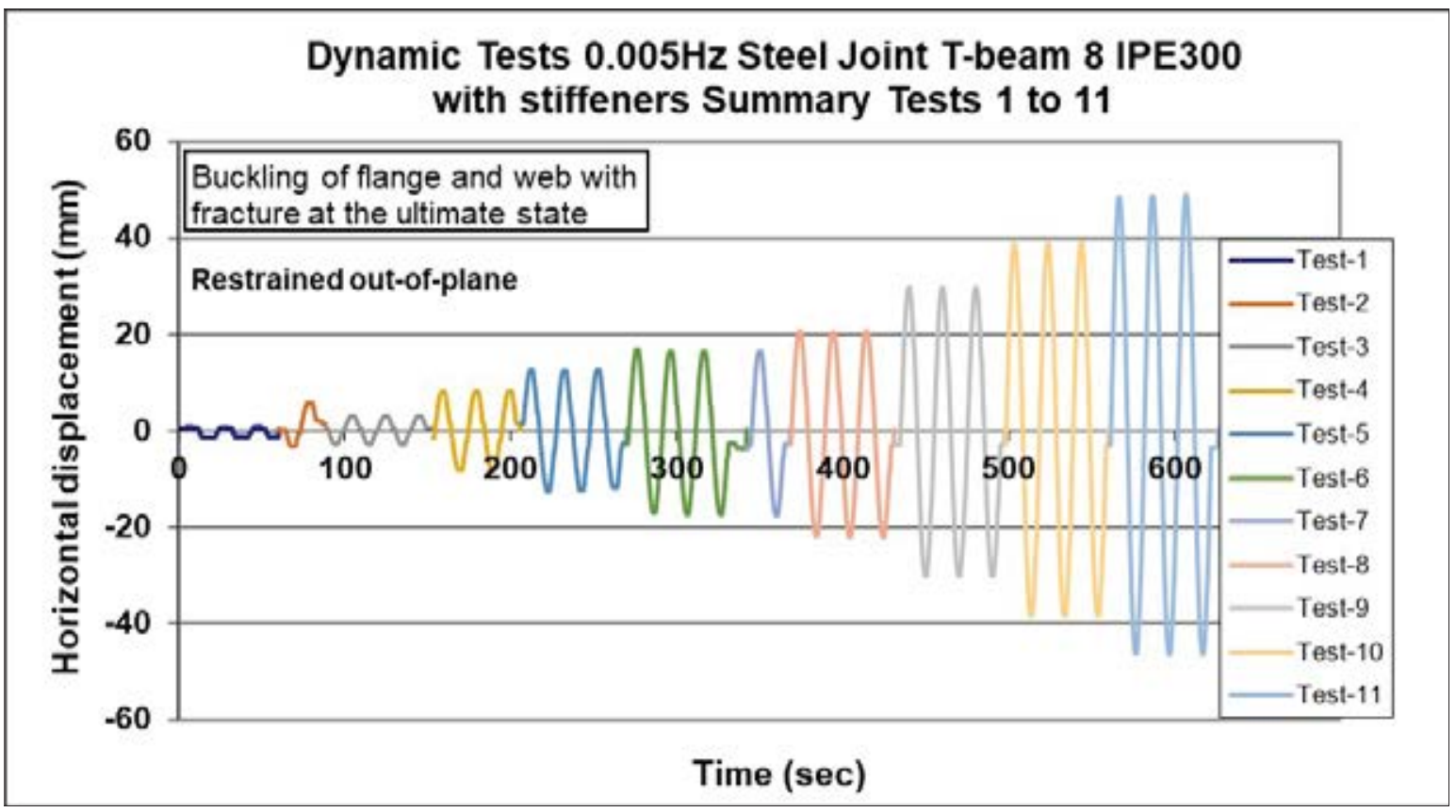

Figure 9: Horizontal displacement at the top of specimen T-Beam 8 due to the plastic rotation at the plastic hinge region.

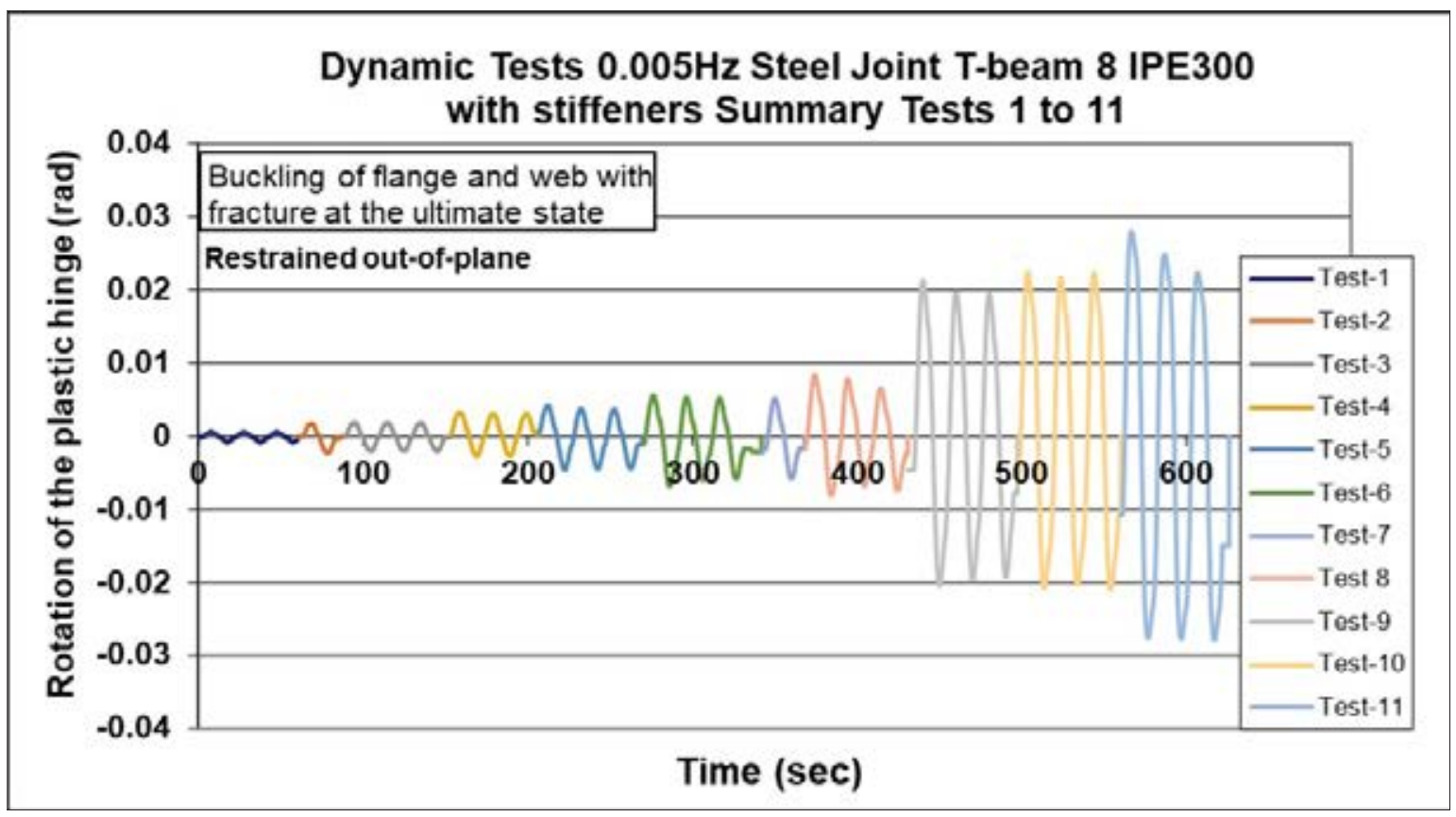

Figure 10: Plastic rotation at the plastic hinge region due to horizontal displacement at the top of specimen TBeam8. 


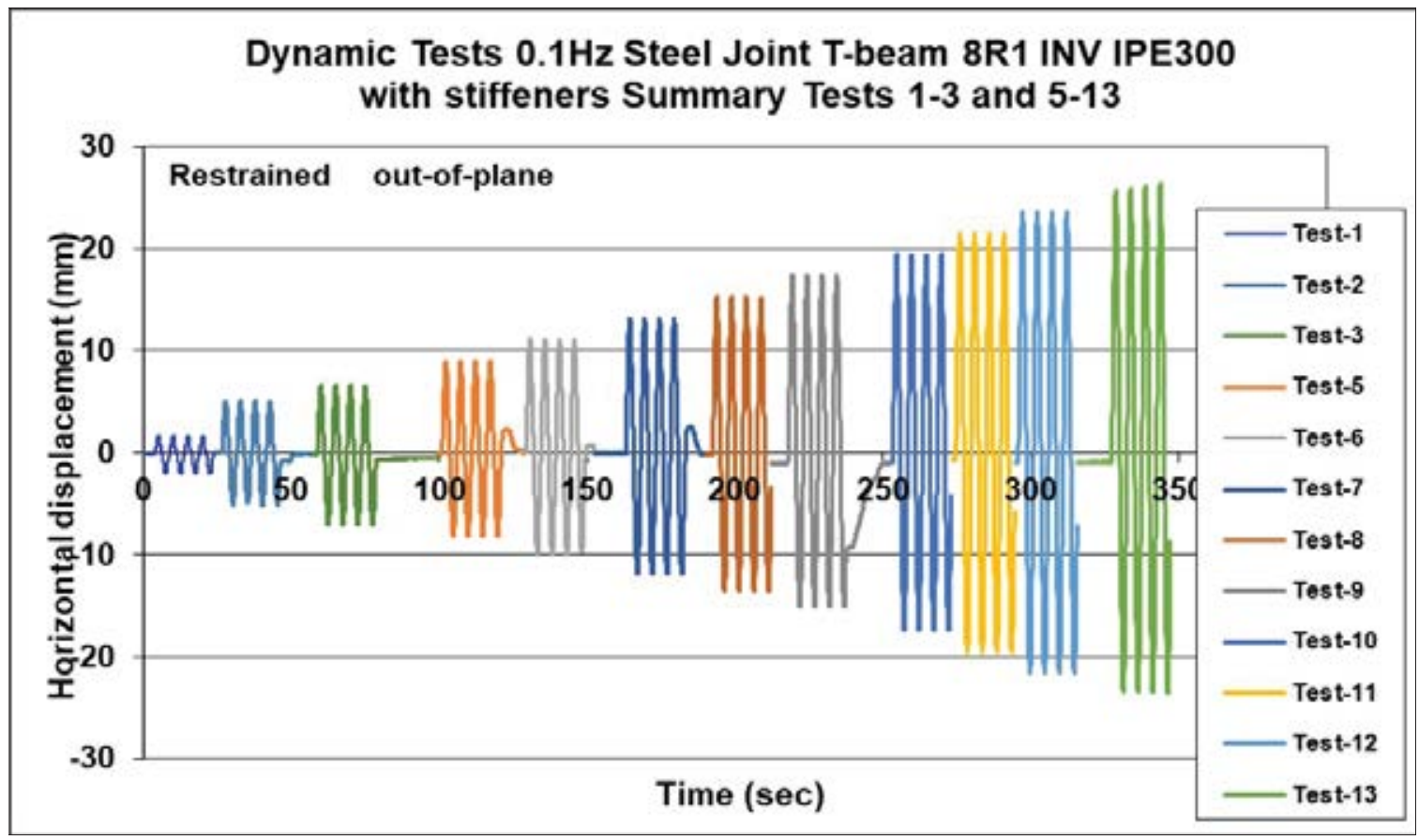

Figure 11: Horizontal displacement at the top of specimen T-Beam8R1 INV due to the plastic rotation at the plastic hinge region.

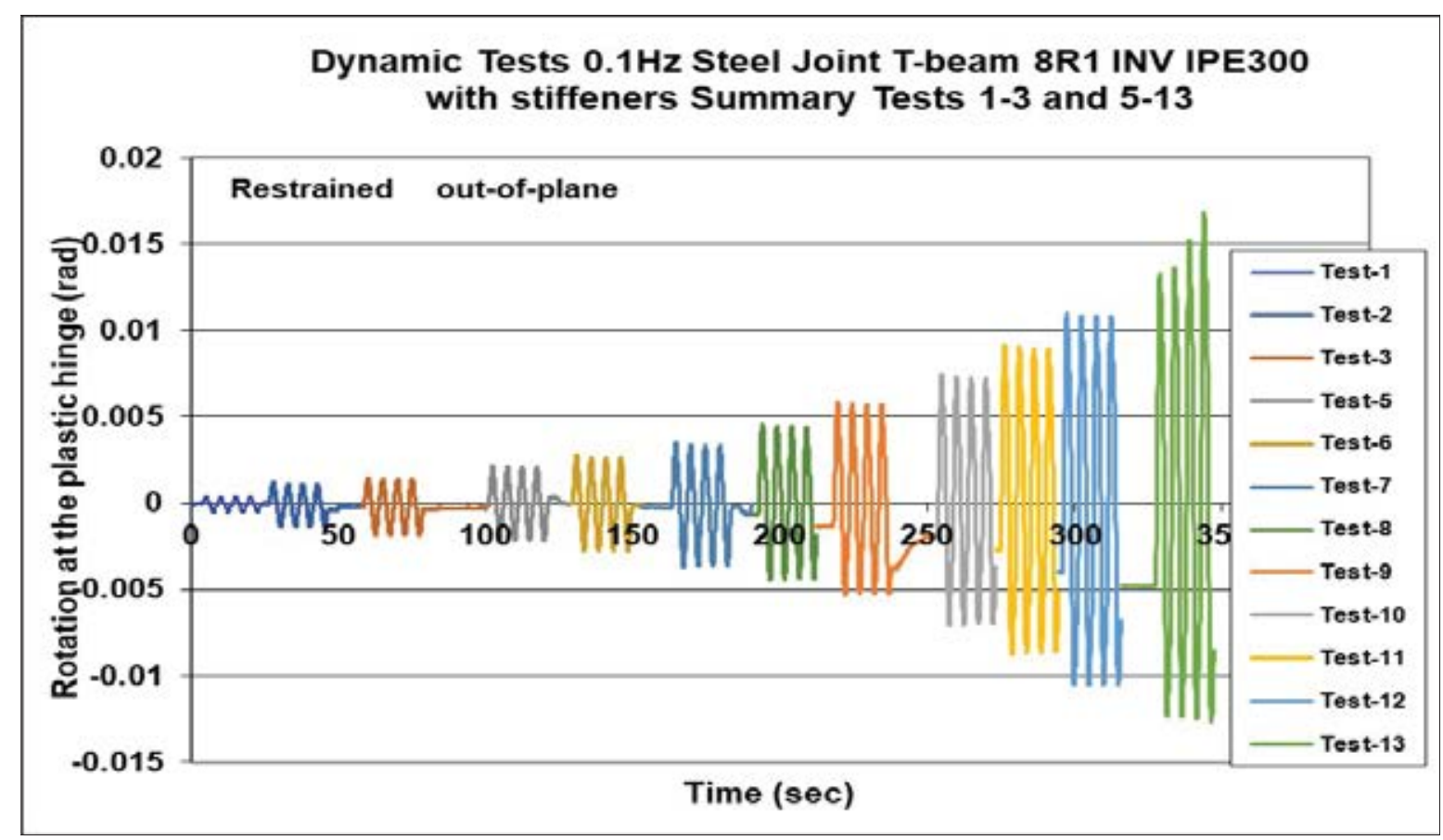

Figure 12: Plastic rotation at the plastic hinge region due to horizontal displacement at the top of specimen T-Beam 8R1 INV.

As can be seen in figures 10 and 12 specimen T-Beam 8 reaches the flexural plastic limit for plastic hinge rotations of the order of 0.027 radians and specimen T-Beam 8R1 INV of the order of 0.015 radian, having undergone a considerable number of low-fatigue cycles 
$[10,13,14]$. Moreover, both specimens failed by developing local instability at the plastic region in the form of flange local buckling and eventually fracture. Figures 13 and 14 portray the observed cyclic response in terms of bending moment and plastic hinge rotation, for specimens T-Beam 8 and T-Beam 8R1 INV, respectively. The bending moment values were deduced at a section above the stiffeners from the measured horizontal load.

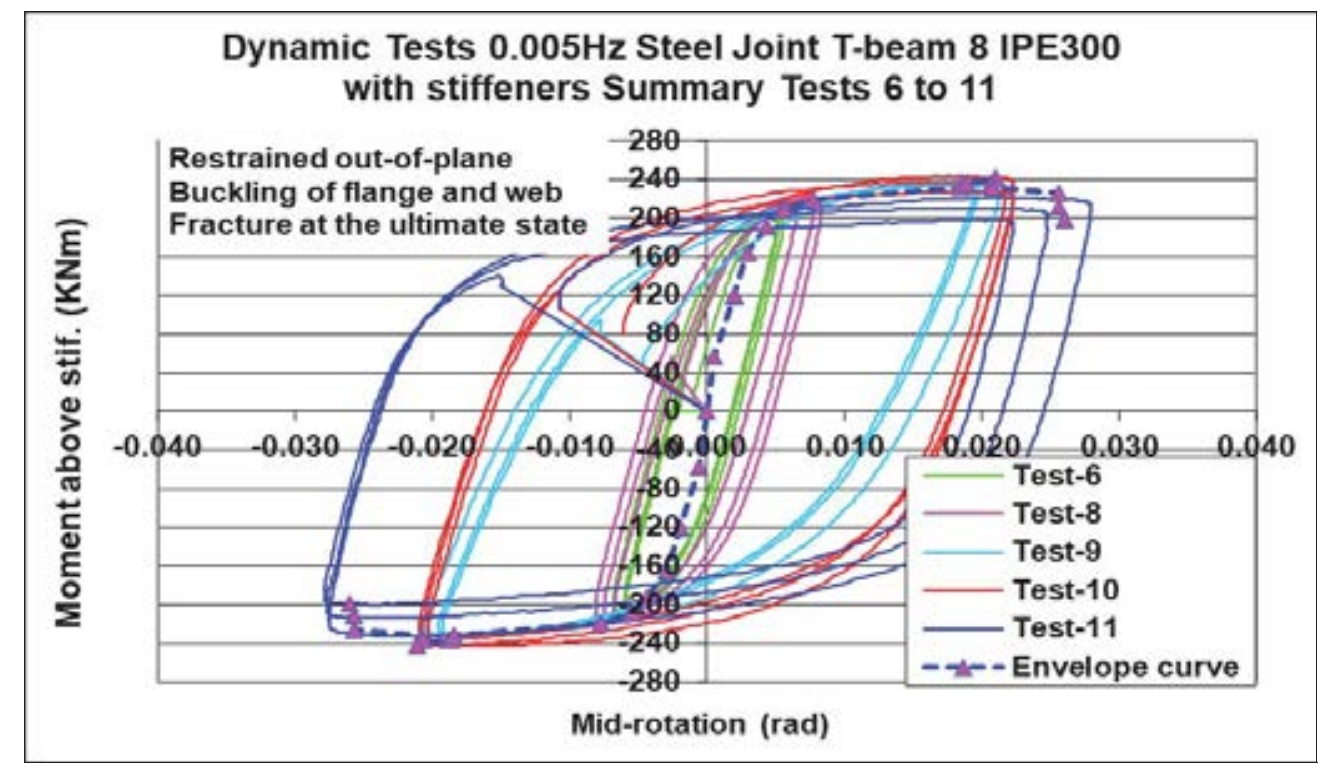

Figure 13: Measured cyclic response of the plastic hinge for specimen T-Bea 8.

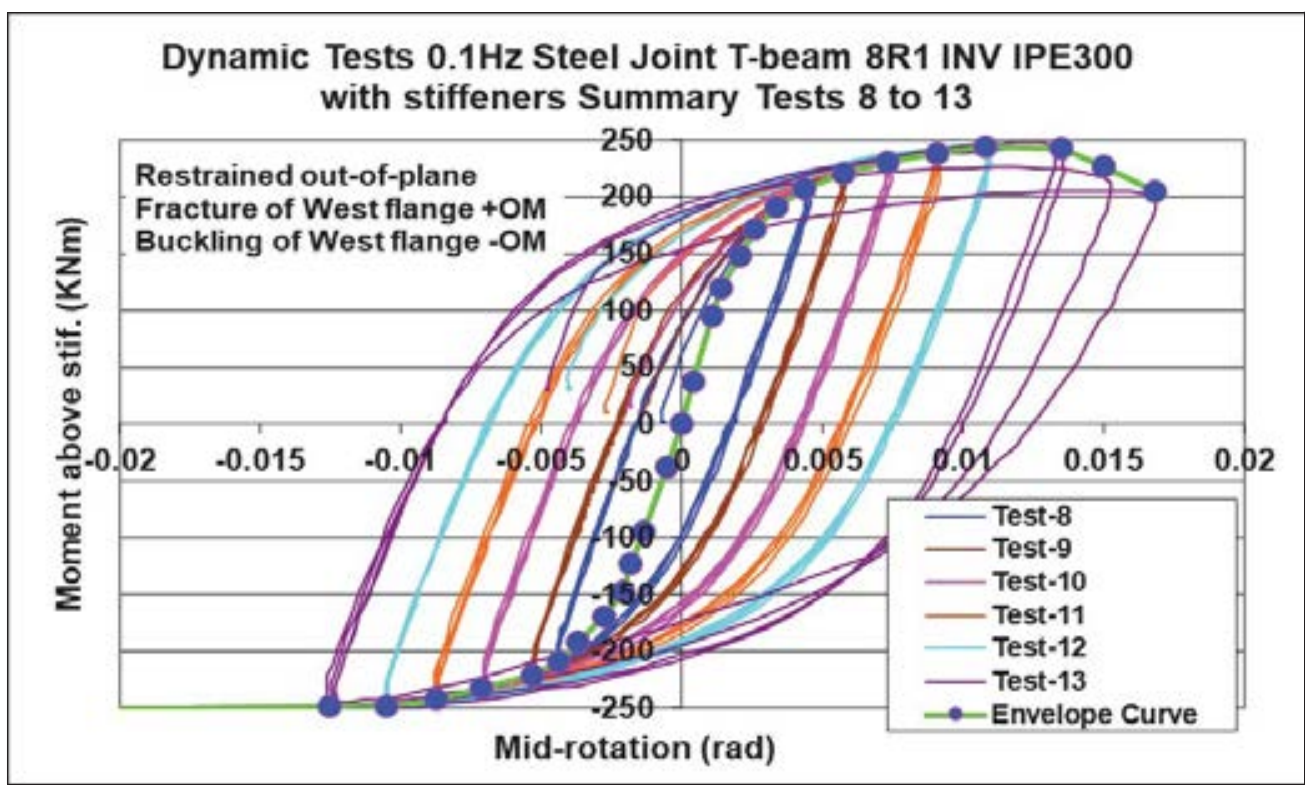

Figure 14: Measured cyclic response of the plastic hinge for specimen T-Beam 8R1 INV.

In both figures 13 and 14 a corresponding envelop curve is also plotted with a dashed blue line for T-Beam 8 specimen and a green line for T-Beam 8R1 INV specimen. As can be seen, both specimens developed large cycles of stable plastic response before reaching their failure mode thus dissipating considerable energy in terms of hysteretic damping. Figure 15 
depicts this hysteretic cyclic response through the corresponding envelop curves. As can be seen from the comparison of these two envelope curves in figure 17 there is a slight difference in the specimens performance in terms of maximum flexural baring capacity and plastic hinge rotation corresponding to that flexural capacity. The measured flexural capacity is of the order of $244 \mathrm{KNm}$ and $248 \mathrm{KNm}$ for specimens T-Beam 8 and T-Beam 8R1 INV, respectively. The plastic hinge rotation values corresponding to these flexural capacity values are for the TBeam 8 specimen approximately 0.018 rad and for the T-Beam 8R1 INV specimen approximately 0.012 rad. Consequently, it can be concluded that the variation in the loading frequency from $0.005 \mathrm{~Hz}$ of the T-Beam 8 specimen to $0.1 \mathrm{~Hz}$ of the T-Beam $8 \mathrm{R} 1 \mathrm{INV}$ specimen led to a decrease in the value of the plastic hinge rotation of the maximum flexural baring capacity with the increase of the loading frequency. Finally from the overall envelope curve a slight increase in the flexural capacity of T-Beam 8R1 INV specimen can be observed with increasing loading frequency and increasing strain rate.

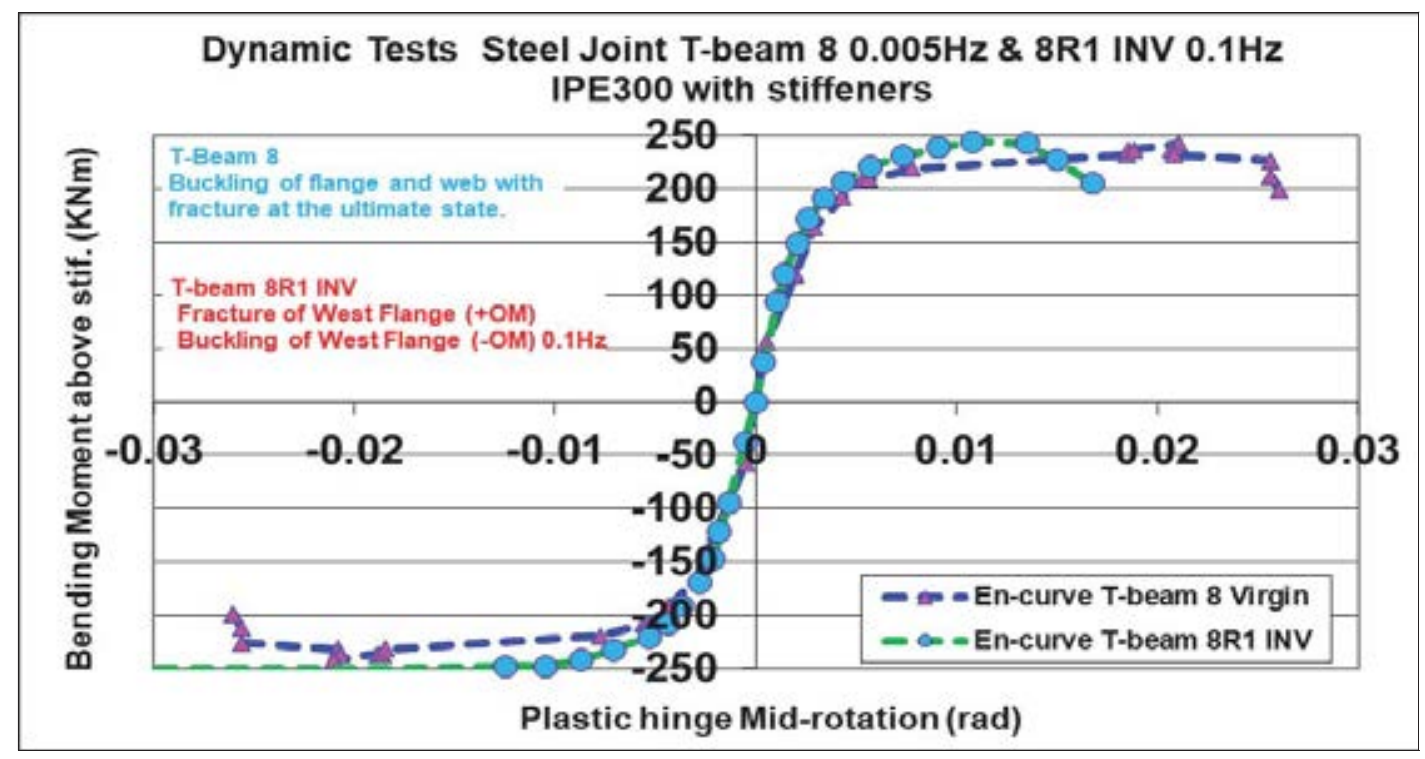

Figure 15: Measured cyclic response of the plastic hinge in terms of envelop curves for both specimens T-Beam 8 and T-Beam 8R1 INV.

\section{NUMERICAL SIMULATION OF THE OBSERVED CYCLIC RESPONSE AND PERFORMANCE}

\subsection{Numerical modeling.}

The commercial software ABAQUS [16] was utilized in this numerical simulation effort. In doing so, the IPE 300 beam part of the experimental sequence was reproduced through the finite element representation as accurately as possible. This is shown in figure 16 whereby it can be seen that the numerical simulation extended all the way from the top section where the horizontal load was imposed to the bottom horizontal section where the IPE 300 beam was welded to the base plate. Moreover, the triangular stiffeners with their actual thickness and geometry were also included in this numerical simulation. The whole surface of the IPE 300 and the stiffeners at the bottom level where the specimens were welded to the base plate was considered to be represented with absolute fixity conditions in the numerical simulation. In addition, the horizontal displacement of the specimen outside the loading plane was con- 
strained. The discretization scheme that was adopted was considerably fine in an effort to be able to catch numerically the observed local modes of buckling of the flanges in the plastic hinge region.

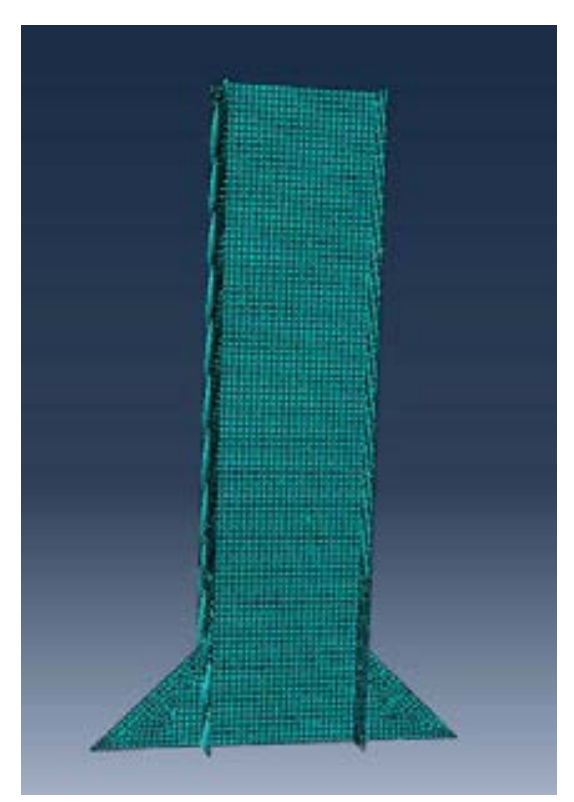

Figure 16: Employed numerical model.

\subsection{Material modeling}

In the framework of the numerical investigation a parametric study was conducted that focused on the way the steel material properties were introduced in the numerical simulation. Two different approaches were tried. According to the first approach the measured tensile steel properties were introduced in the numerical simulation through the Abaqus isotropic hardening parameters whereas in the second approach the measured properties were modified accordingly in order to be introduced in the numerical simulation through the ABAQUS combined hardening material model [16]. More information on this approach can be obtained from the previous work by Manos G.C. at al [19].

In thi $\sigma$ work the focus relies in the numerical simulation of the material tests through the ABAQUS combined hardening material constitutive law. There are several ways in this commercial software package [16] to define a combined hardening material constitutive law in order to capture the cyclic response of a specimen. The evolution law of this model consists of two components: a nonlinear kinematic hardening component, which describes the translation of the yield surface in stress space through the back-stress, and an isotropic hardening component, which describes the change of the equivalent stress defining the size of the yield surface, as a function of plastic deformation [16]. In this study the combined hardening constitutive law is defined through the values that are given to certain relevant parameters. Values for these parameters were calculated from the test data that were obtained from the experimental process from the tests of steel samples that were taken from the T-Beam specimens and can be seen in the work by Manos G.C and Nalmpantidou A. [18] .

This software (Abaqus) allows the specification of strain rates effects with the option of rate dependent data at combined and isotropic hardening constitutive law. In order to define the strain rate effect the use of a dynamic increase factor (DIF) was utilized based on the work of Malvar and Crawford [9]. The work of Malvar and Crawford [20] is based on numerous 
experimental data from a literature review on the effects of strain rates on the properties of steel reinforcing bars for reinforced concrete structural elements. The dynamic increase factor (DIF) is the amplification by DIF of the value a certain mechanical property (yield stress or maximum stress) has under low strain rate loading conditions (static) to another condition whereby because of the nature of loading (dynamic) the strain rate has a larger value than before. A relationship is proposed by Malvar and Crawford [20] that a DIF value can be derived for a given strain rate increase and thus evaluate through this DIF the corresponding for this increased strain rate amplified yield and ultimate stress values. Figure 17 depicts the dynamic increase factor considered for the numerical simulation.

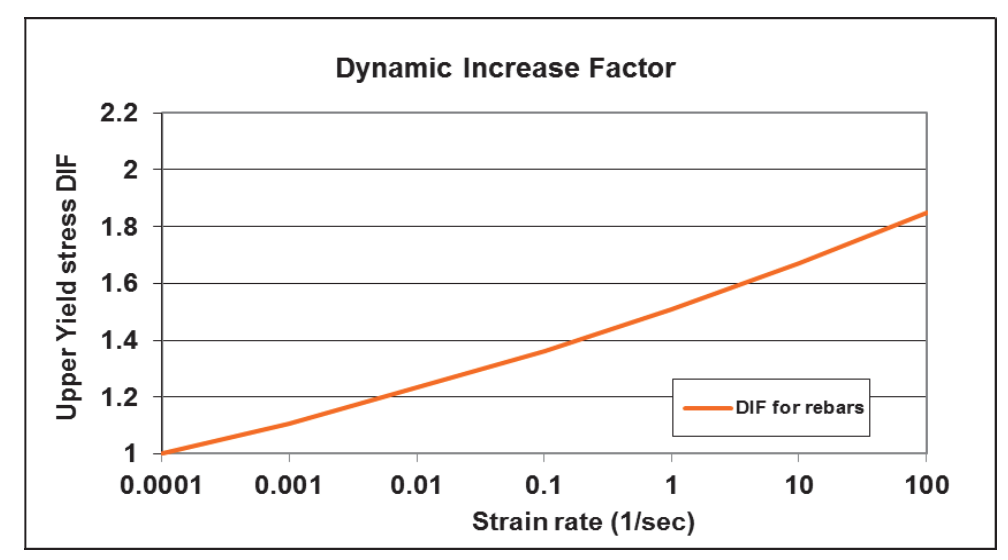

Figure 17. Dynamic increase factor which have been considered for the numerical investigation

\subsection{Numerical results from the parametric study}

This section will present numerical results of the experimental investigation carried out with T-Beam 8 and T-Beam 8R1 INV under cyclic tests. The necessary material parameters for the numerical simulation were calculated from the experimental data of simple steel coupons taken from T-Beam 8 and are the following:

Combined hardening parameters:

Yield stress at plastic strain $\left.\sigma\right|_{0}=180-200 \mathrm{Mpa}$,

Kinematic Hardening Parameter $\mathrm{C}_{\mathrm{k}}=34000$

Gamma $\gamma_{\mathrm{k}}=250$

Cyclic hardening paraneters:

Equivalent stress $\left.\sigma\right|_{0}=180-200 \mathrm{Mpa}$

Q-Infinity parameter $\mathrm{Q}_{\infty}=85$

Hardening parameter $b_{\text {iso }}=6.5$

Combined hardening parameters:

Yield stress at plastic strain $\left.\sigma\right|_{0}=100-140 \mathrm{Mpa}$,

Kinematic Hardening Parameter $\mathrm{C}_{\mathrm{k}}=51800$

Gamma $\gamma_{\mathrm{k}}=250$

Cyclic hardening paraneters:

Equivalent stress $\left.\sigma\right|_{0}=100-140 \mathrm{Mpa}$

Q-Infinity parameter $\mathrm{Q}_{\infty}=305$ 
Hardening parameter $b_{\text {iso }}=6.5$

Combined hardening parameters:

Yield stress at plastic strain $\left.\sigma\right|_{0}=140 \mathrm{Mpa}$,

Kinematic Hardening Parameter $\mathrm{C}_{\mathrm{k}}=59520$

Gamma $\gamma_{\mathrm{k}}=250$

Cyclic hardening paraneters:

Equivalent stress $\left.\sigma\right|_{0}=140 \mathrm{Mpa}$

Q-Infinity parameter $\mathrm{Q}_{\infty}=30$

Hardening parameter $\mathrm{b}_{\text {iso }}=6.5$

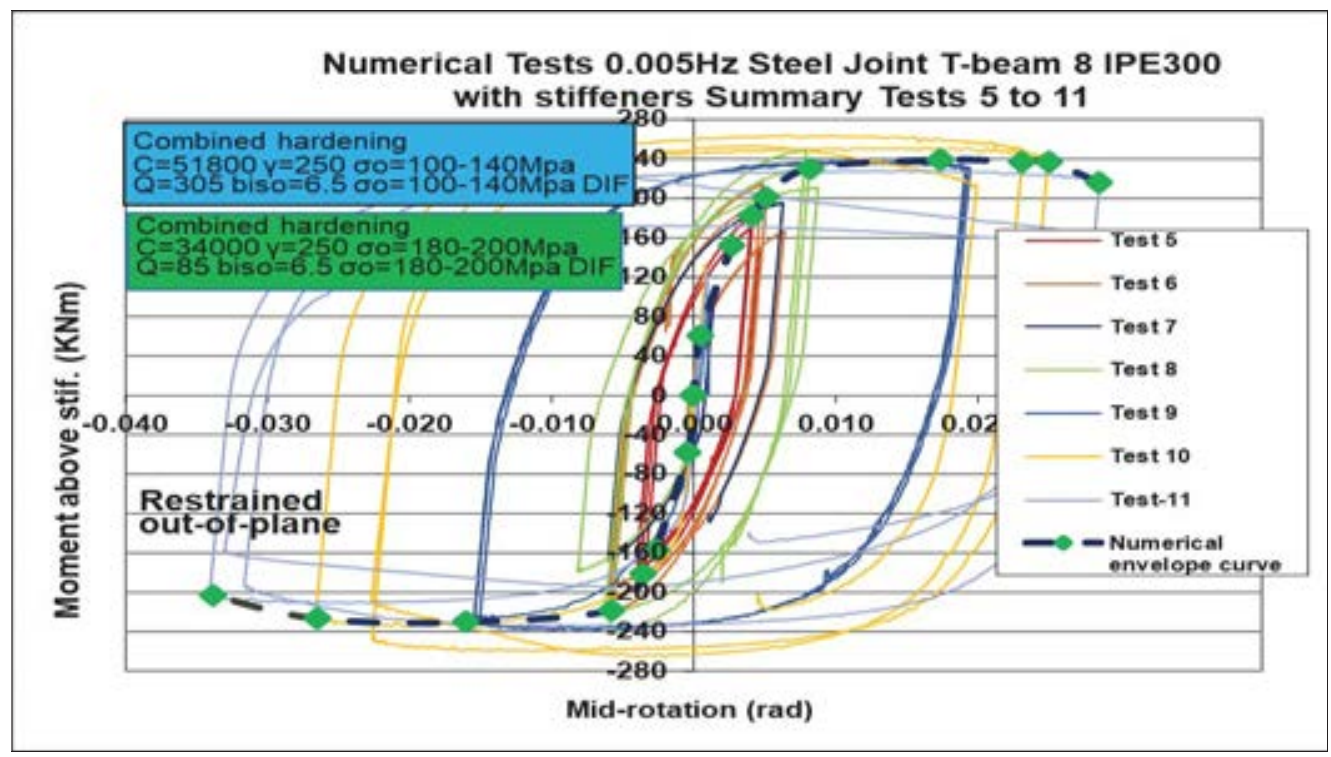

Figure 18. Numerical predictions of the cyclic response of the plastic hinge for specimen T-Beam 8

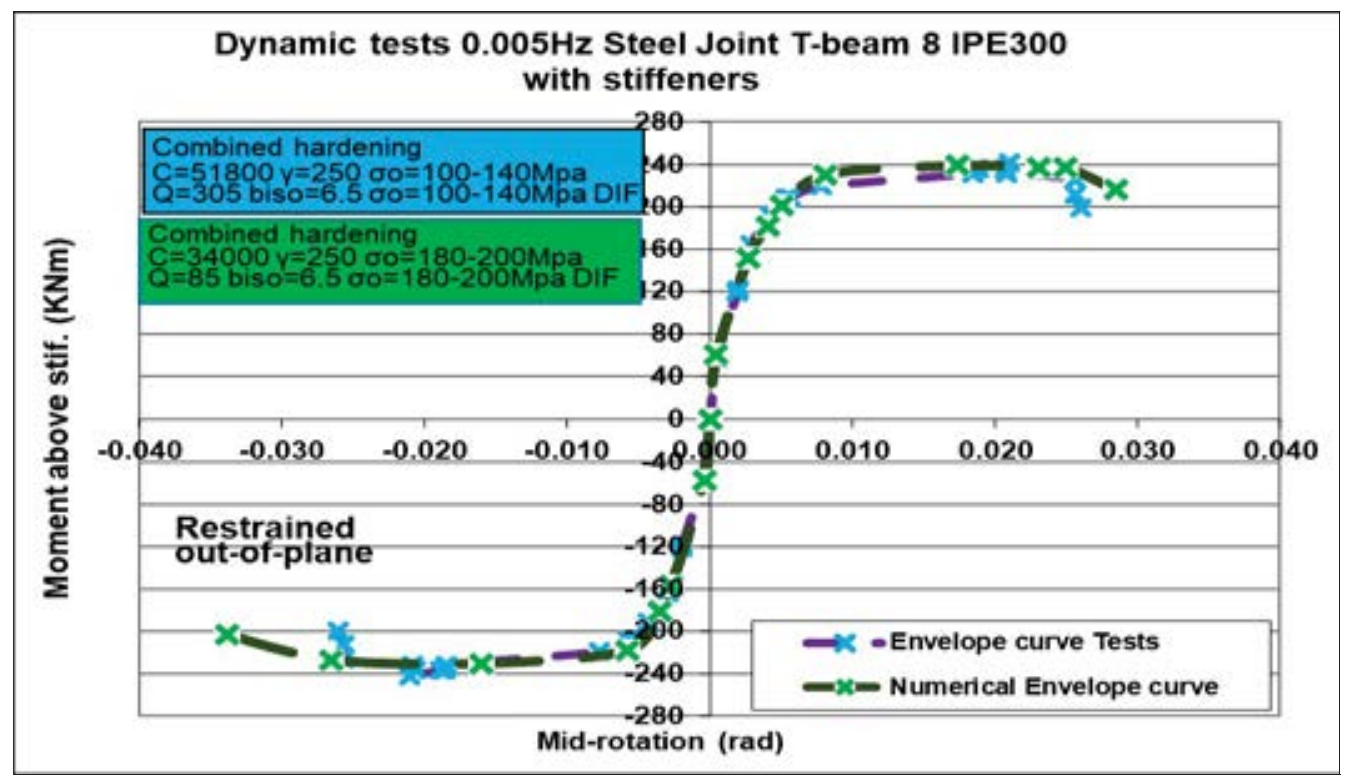

Figure 19. Predicted cyclic response of the plastic hinge in terms of envelope curves for specimen T-Beam 8 together with the measured response 


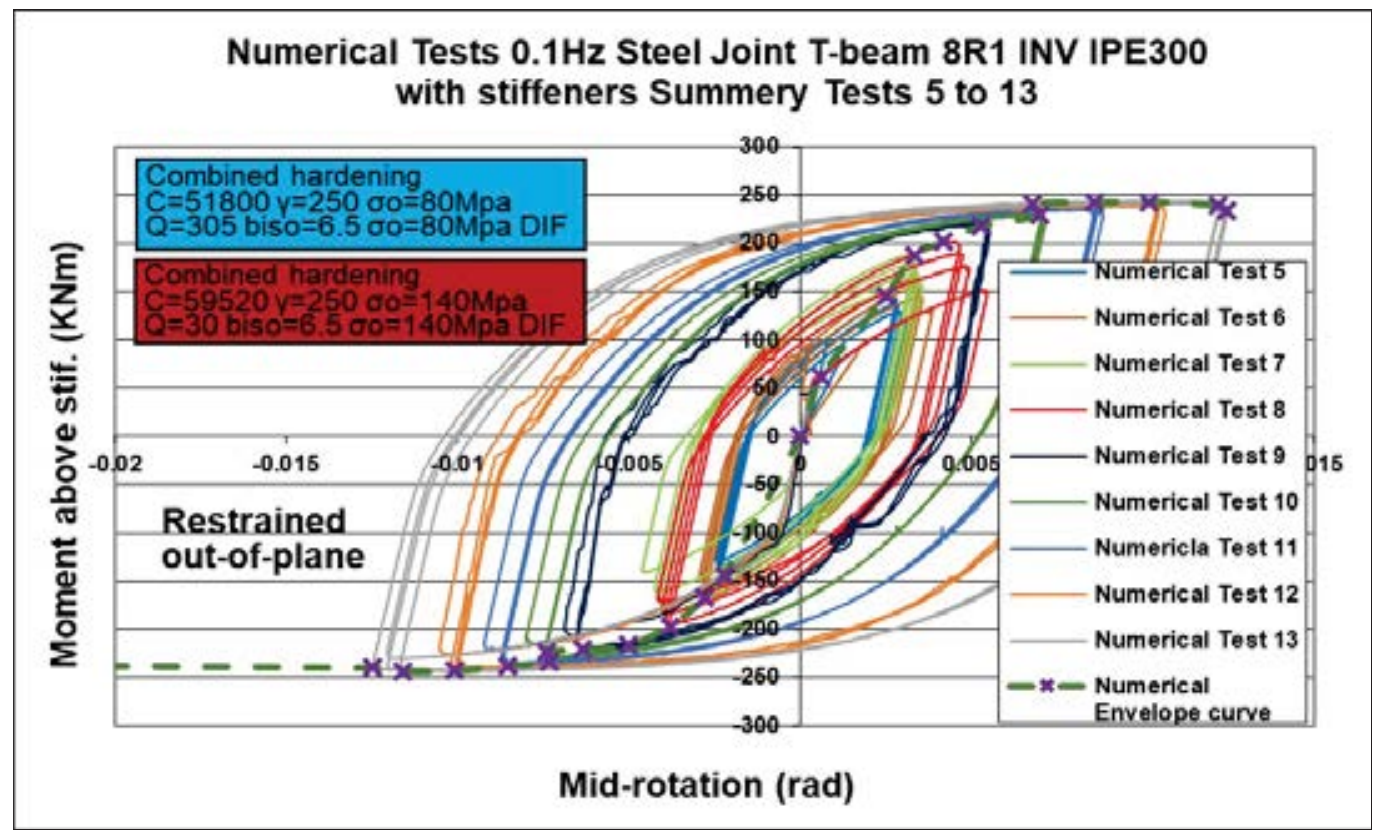

Figure 20. Numerical predictions of the cyclic response of the plastic hinge for specimen T-Beam 8R1 INV

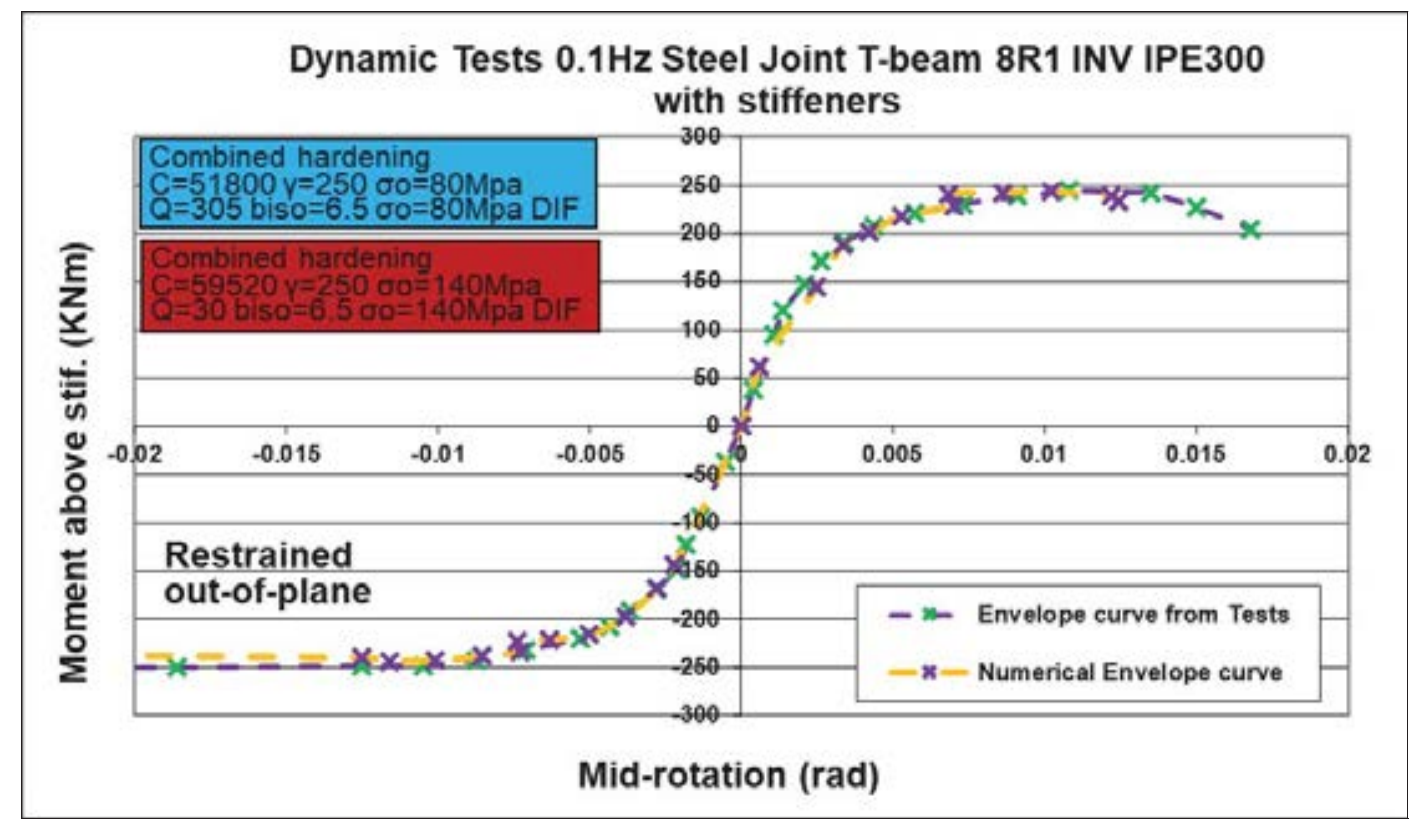

Figure 23. Predicted cyclic response of the plastic hinge in terms of envelope curves for specimen T-Beam 8R1 INV together with the measured response

In figure 18 and 20 are the results of the numerical simulation of T-Beam 8 and T-Beam 8R1 INV and the corresponding envelope curves shown. As can be seen specimen T-Beam 8 reaches the flexural plastic limit for plastic hinge rotations of the order of 0.027 radians and 
specimen T-Beam 8R1 INV of the order of 0.015 radian, having undergone the same number of low-fatigue cycles $[10,13,14]$ as the experimental setup.

Figure 19 and 21 compare the envelop curves predicted by the numerical simulation for specimens T-Beam 8 and T-Beam $8 \mathrm{R} 1 \mathrm{INV}$, respectively, with the corresponding envelop curves of the measured cyclic response for the same specimens. The predicted response was obtained by using the combined hardening material model and as can be seen there is a small variation between the measured flexural capacity and rotation at the plastic hinge and the numerical simulation with higher values of the numerical simulation for T-Beam 8 specimen. Furthermore the predicted cyclic response of T-Beam 8R1 INV has a quite good agreement between the measured flexural capacity and rotation at the plastic hinge and the numerical simulation.

\section{CONCLUSIONS}

- The seismic performance of a steel beam-to-column connection was studied by subjecting two specimens of such steel beam-to-column connection specimens to imposed cyclic displacements with a variety of low to medium range strain rates. The tested specimens were constructed with prototype steel sections welded in a typical fashion.

- Both specimens developed local flange buckling modes of failure for plastic hinge rotation values approximately equal 0.027 radians for T-Beam 8 specimen and 0.015 radians for T-Beam 8R1 INV specimen. For values of plastic hinge rotation higher than 0.027 radians for T-Beam 8 specimen and 0.15 radians for T-Beam 8 R1 INV specimen the deterioration of the flexural capacity became substantial for both specimens as the local flange buckling mode of failure prevailed.

- The consequence of the previous observation is that the employed strain rate variation in the used loading sequence of specimen T-Beam 8 with $0.005 \mathrm{~Hz}$ from that of the loading sequence of specimen T-Beam 8R1 INV with $0.1 \mathrm{~Hz}$ led to a decrease in the value of the plastic hinge rotation of the maximum flexural baring capacity with the increase of the loading frequency. From the overall envelope curve a slight increase in the flexural capacity of T-Beam 8R1 INV specimen can also be observed with increasing loading frequency and increasing strain rate. However, this is a partial conclusions based on rather limited data. Therefore more research is needed to further investigate the strain rate influence on the beam-to-column connections earthquake performance.

- The numerical simulation of the tested specimens utilizing the capabilities of a commercial software package yielded reasonable good agreement between both the measured and predicted cyclic response in terms of maximum flexural capacity, dissipation characteristics and deterioration of the flexural capacity. It is of utmost importance to have realistic estimates of the values of the parameters are $\left.\sigma\right|_{0}$ (yield stress at zero equivalent plastic strain), $C_{k}$ and $\gamma_{k}$ (material constants) which define the steel combined hardening material behaviour.

\section{ACKNOWLEDGEMENTS}

The authors would like to acknowledge the assistance of M. Theofanous, Dr. Civil Engineer, Lecturer at the Department of Civil Engineering of the University of Birmingham, for all his valuable advice related to the numerical simulation. The technical assistance of $\mathrm{T}$. 
Koukouftopoulos in preparing the experimental arrangement is also gratefully acknowledged.

- To the memory of Hiroshi Akiyama, Professor of the University of Tokyo, Japan and of Heki Shibata, Professor of Industrial Science, University of Tokyo, Japan.

\section{REFERENCES}

[1] Akiyama H. Earthquake-Resistant Limit-State Design for Buildings. University of Tokyo Press: Tokyo, 1985.

[2] Anastasiadis A., Mosoarca M., Gioncu V., Mazzolani F. M., "Some thoughts for the prediction of the local inelastic capacity of MRF subjected to seismic actions", $8^{\text {th }}$ STESSA Conf. on the Behavior of Steel Structures in Seismic Areas, Tongji Univ., Songhai China, July 2015.

[3] Anastasiadis A, Gioncu V, Mazzolani FM. "New trends in the evaluation of available ductility of steel members." Behavior of Steel Structures in Seismic Areas STESSA $2000 ; 3-26$.

[4] Anderson, James C., Nastar Navid, Rojas Fabian, "Low-Cycle Fatigue Effects on Steel Moment Frames", Safety, Reliability and Risk of Structures, Infrastructures and Engineering Systems - Furuta, Frangopol \& Shinozuka (eds)(C) 2010 Taylor \& Francis Group, London, ISBN 978-0-415-47557-0

[5] Ballio Giulio \&. Castiglioni, Carlo A, "Seismic Behaviour of Steel Sections", J. Construct. Steel Research 29 (1994) 21-54

[6] Castiglioni Carlo A., Mouzakis Harris P.,. Carydis Panayotis Gr. (2007): "Constant and Variable Amplitude Cyclic Behavior of Welded Steel Beam-to-Column Connections", Journal of Earthquake Engineering, 11:876-902, 2007, 11:6, 876-902, doi.org/10.1080/13632460601188027.

[7] Clark P, Frank K, Krawinkler H, Shaw R. Protocol for fabrication, inspection, testing, and documentation of beam-column connection tests and other experimental specimens. SAC Steel Project Background Document, Report No. SAC/BD-97/02, 1997.

[8] El Hassouni A, Plumier A., Cherrabi A. "Experimental and numerical analysis of the strain-rate effect on fully welded connections", Journal of Constructional Steel Research (2010), doi 10.1016/j.jcsr.2010.09.02

[9] Federal Emergency Management Agency. Interim testing protocols for determining seismic performance characteristics of structural and nonstructural components. FEMA 461 Draft Document, Applied Technology Council, Redwood City, CA, 2007.

[10] Gioncu V, Petcu D. "Available rotation capacity of wide-flange beam and beamcolumns part 1, 2.", Journal of Constructional Steel Research 1997; 43: 161-244.

[11] Krawinkler H. Loading histories for cyclic tests in support of performance assessment of structural components. The 3rd International Conference on Advances in Experimental Structural Engineering, San Francisco, 2009. 
[12] Lamarche Charles-Philippe and Tremblay Robert, "Seismically induced cyclic buckling of steel columns including residual-stress and strain-rate effects", Journal of Constructional Steel Research 67 (2011) 1401-1410, doi:10.1016/j.jcsr.2010.10.008

[13] Lee Kyungkoo and Stojadinovic Bozidar, "Low-cycle fatigue limit on seismic rotation capacity for US steel moment connections", 13th World Conference on Earthquake Engineering, Vancouver, B.C., Canada, August 1-6, 2004, Paper No. 90.

[14] Vayas I. "Investigation of the cyclic behavior of steel beams by application of low-cycle fatigue criteria." Behavior of Steel Structures in Seismic Areas STESSA 1997; 350-357.

[15] Yu Jiao, Satoshi Yamada, Shoichi Kishiki and Yuko Shimada, "Evaluation of plastic energy dissipation capacity of steel beams suffering ductile fracture under various loading histories" Earthquake Engng Struct. Dyn. 2011; 40:1553-1570.

[16] Hibbitt, Karlsson, Sorensen. Inc. ABAQUS user's manual volumes I-V and ABAQUS CAE manual. Version 6.10.1. Pawtucket, USA; 2010.

[17] Nip, K.H., Gardner L., Davies C.M., Elghazouli A.Y., "Extremely low cycle fatigue tests on structural carbon steel and stainless steel", Journal of Constructional Steel Research 66 (2010) 96-110, doi:10.1016/j.jcsr.2009.08.004

[18] Nalmpantidou A., Manos G.C., "Experimental and numerical investigation of the plastic cyclic behavior of simple steel coupons", COMPDYN 2021, Streamed from Athens, Greece, June 2021

[19] Manos G.C., A. Nalmpantidou, V.Kourtides, A. Anastasiadis "Cyclic response of a steel beam to column connections - an experimental and numerical study", COMPDYN 2015, Crete Island, Greece, May 2015

[20] Malvar, L. J. and John E. Crawford J. E., "Dynamic increase factor for steel reinforcing bars", Twenty-Eighth DDESB Seminar, Orlando, FL., 1998 